This item was submitted to Loughborough's Research Repository by the author.

Items in Figshare are protected by copyright, with all rights reserved, unless otherwise indicated.

\title{
Do the Olympic Games promote dietary health for spectators? An interdisciplinary study of health promotion through sport
}

\section{PLEASE CITE THE PUBLISHED VERSION}

https://doi.org/10.1080/16184742.2018.1562484

\section{PUBLISHER}

Taylor \& Francis (Routledge)

\section{VERSION}

AM (Accepted Manuscript)

\section{PUBLISHER STATEMENT}

This is an Accepted Manuscript of an article published by Taylor \& Francis in European Sport Management Quarterly on 8 January 2019, available online: http://www.tandfonline.com/10.1080/16184742.2018.1562484.

\section{LICENCE}

CC BY-NC-ND 4.0

\section{REPOSITORY RECORD}

Piggin, Joe, Doralice Souza, Sabrina Furtado, Matheus Milanez, George Cunha, Bruno H. Louzada, Billy Graeff-Bastos, and Haifa Tilii. 2019. "Do the Olympic Games Promote Dietary Health for Spectators? an Interdisciplinary Study of Health Promotion Through Sport". Loughborough University. https://hdl.handle.net/2134/36418. 


\title{
Do the Olympic Games promote dietary health for spectators? An interdisciplinary study of health promotion through sport.
}

\begin{abstract}
Research question: Debates about dietary health promotion at sports events are becoming more prominent and are making food and drink sport sponsorship arrangements increasingly problematic. This study uses choice architecture as a guiding framework to examine how ideas about 'healthy choices' for customer food and drink were operationalised at the Rio 2016 Olympic and Paralympic Games in Brazil.
\end{abstract}

Research methods: An interdisciplinary perspective was applied, whereby considerations of public health, marketing, psychology, policy studies, nutrition and event management informed the research. A multi-method approach was utilised, which included policy analysis, menu analysis, event process analysis, and interviews with spectators. The data were compared and contrasted to see how ideas about health manifested in policy and practice, culminating in the Rio 2016 event.

Results and findings: While 'healthy choice' claims featured prominently in Rio 2016 policy, the practical reality consisted of spaces with both a very low amount of choice for Olympic spectators, and a large amount of high- and ultra-processed food. Rio 2016 organisers shaped the choice architecture so that the food and drink being sold and consumed met neither the spectators' nor Brazilian policy definitions of health.

Implications: The results show a need for organisers of sport events to question and challenge popular claims of health promotion. Recommendations for governments and sport organisations include the need to alter the accepted production practices of sport mega events, especially since the events are often in receipt of public money and involve unfulfilled claims about health promotion. 


\section{Sport and health promotion}

Poor nutrition can lead to reduced immunity, increased susceptibility to disease, impaired physical and mental development, and reduced productivity from a range of noncommunicable diseases (World Health Organisation, 2016). Health agencies have recently warned against the health implications of poor diets in all countries (United Nations, 2014). As well as the deleterious physical health consequences, the Brazilian Department of Health suggests that ultra-processed foods damage culture, social life, and the environment (Brazil Ministry of Health, 2014).

Sport events in particular are implicated in this global health issue of poor nutrition. Many sport mega events (SMEs) have significant financial relationships with food and drink companies, and events such as the Olympic and Paralympic Games are increasingly framed as being able to promote healthy lifestyles (International Olympic Committee, 2015; World Health Organisation, 2012). However, relationships between food and drink companies and sport events are increasingly seen as problematic, due to the perception that the products being endorsed are not healthy (Bragg et al., 2013; Harris, Pomeranz, Lobstein, \& Brownell, 2009; Ireland \& Watkins, 2010; Lancet, 2012). Research on the relationship between sport and food sponsorship suggests that 'sponsorship relationships between sporting organisations and food and beverage brands and companies do not always reinforce either sports-related or more general nutrition recommendations' (Carter, Signal, Edwards, Hoek, \& Maher, 2013, p. 2). When energy-dense, nutrient-poor food companies endorse events, teams and athletes, this can imply that consumption of these foods is commensurate with success, sport and health ideals.

There is a paucity of research on the conflicting values regarding health promotion through sport, and given the health problems often connected with poor nutrition it is pertinent for sport management scholars and practitioners to engage with this issue. An 
appreciation of the effects of health promotion through sport would give scholars a more holistic view of criteria for event success. For practitioners, a deeper appreciation includes an opportunity to harness the often-claimed health benefits of sport for the customers and fans they wish to retain. Some research has focused particularly on young people and their potential susceptibility to corporate sponsorship through sport (Bragg et al., 2018). Recent research suggests that sports sponsorship by alcohol and fast food companies can effectively reach child audiences (Pettigrew, Rosenberg, Ferguson, Houghton, \& Wood, 2012). Therefore, the policies which inform SMEs, the details of SME sponsorship campaigns and the corporate strategies used to connect sponsorship contracts and the public deserve critical scrutiny. Nutritional health of spectators has not necessarily been high on the agenda of sport management research. Referring to sport management literature specifically, Henderson (2009) noted that the focus over the past 20 years 'has been primarily concerned with topics related to sports as spectatorship or entertainment and not sports as opportunities to engage mass participation in active behaviours that can lead to better health' (p. 58). This present research fulfils three aims. First, this research aims to fill a specific gap in sport management literature. It examines how ideas about health promotion and healthy choices for customers at sport events are put into practice at the world's largest mega event - the 2016 Olympic and Paralympic Games in Brazil. Second, this empirical investigation offers a novel insight into how interdisciplinary research can be conducted in a sport management milieu. Third, it utilises a potentially useful conceptual framework of 'choice architecture' which may appeal to sport management scholars in future studies.

\section{The Olympic Games as a site of consumption and critique}

Researchers and health advocates are increasingly lobbying for change in the food environment in general and at sport events in particular. A New Zealand study concluded that 
public health mechanisms, such as healthy food and beverage policies, and widely promoting water as the beverage of choice in sport, should form part of a comprehensive public health approach to reduce the substantial, unnecessary and potentially harmful effects of sugarsweetened beverages (Smith, Jenkin, Signal, \& Mclean, 2014). The World Health Organisation Commission to Ending Childhood Obesity recently argued that both young people and adults are negatively affected by unhealthy food messages. The Commission argues that settings where children and adolescents gather, such as sports facilities or events, should be free of marketing of unhealthy foods and sugar-sweetened beverages. (2014). And there appears to be some change in the status quo in some contexts. For instance, the Amsterdam City Council in the Netherlands has begun refusing sponsorship to events that take money from Coca Cola or McDonald's (Boseley 2017).

At the same time, the Olympics are maintained in part by major sponsors, with their brands being heavily promoted at events. The International Olympic Committee (2016a) claims that the 'Olympic Games are one of the most effective international marketing platforms in the world, reaching billions of people in over 200 countries and territories throughout the world.' An inherent part of the spectacle is that organisers and the sponsoring companies promote specific ideas about consumption through marketing campaigns and provision of food and drink to spectators. Importantly, for many years the IOC has promoted healthy diets as part of their aspirations. In 1999, an IOC document (published in partnership with the Shell corporation) named Agenda 21: Sport for Sustainable Development endorsed basic food and nutrition standards to ensure everyone has access to adequate and healthy food (IOC, 1999). Further, the IOC argued that catering at these events should set an example for sustainable development and 'make use of goods and foods that have been created with due respect for the development of the local population' (p. 38). Therefore, as the world's largest and most well-known sport event, the Olympic Games (and the associated Paralympic 
Games), and more specifically Rio 2016 are worthy of investigation for various reasons. Both external forces (such as global concerns about healthy eating noted above) and the IOC's own pronouncements connect and implicate the event with health promotion. Further, the Rio 2016 event was particularly appropriate to study because the Rio 2016 organisers produced a strategy to promote health through food and drink at the event. This provided an opportunity to investigate how the plan was implemented over time. Also, while not a deciding factor for focusing on Rio 2016, its setting in Brazil provided an opportunity to observe how a large sport event could manifest in a country with significant wealth disparities and associated health disparities and concerns.

Some limited analysis has been conducted into the (lack of) explicit health promotion at Olympic events. Soteriades et al (2006) noted Ministries of the Greek government used brochures and CD-ROMs to promote the Mediterranean diet leading up to the Athens 2004 Olympic and Paralympic Games, and held an exhibit of traditional food products for journalists and the general population. Also, sponsors produced a brochure on diet which was targeted at school students. The study suggested there was significant room for improvement in health-promotion programmes during sport events. A self-published review by the IOC of Beijing's 2008 Olympic health legacy included a survey conducted before and after the event which found 'no obvious changes in diet and nutrition' (2010, p. 147). It is apparent therefore that health promotion at sport events is problematic, that a growing body of research suggests there are harmful consequences of sponsorship by food and drink companies, and that the Olympic Games specifically has been criticised for its involvement in this sport and food industrial complex. We also note various analyses of nutrition offerings for Olympic and Paralympic athletes and support staff, as distinct from spectators (Pelly, O'Connor, Denyer, \& Caterson, 2011; Pelly, Meyer, Pearce, Burkhart, \& Burke, 2013). However, to date there have been no in-depth investigations of food and drink for spectators at the Olympic and 
Paralympic Games. Therefore this article questions how ideas about 'healthy choices' for customer food and drink were operationalised at the Rio 2016 Olympic and Paralympic Games in Brazil. Examining how ideas are operationalised or put into practice could provide either best practice systems for future events, or evidence of poor practice which the public, governments and event organisers should be made aware of in order to question and resist and change unfulfilled or misleading health promotion claims.

\section{Choice Architecture}

This research examines the manifestation of ideas about choice and health through the choice architecture at Rio 2016. This concept refers to the framing or presentation of options, from policy to practice (Thaler \& Sunstein, 2009). Therefore, the food options that event spectators have access to will be enabled and constrained by a variety of factors. To name a few, these factors can include the range of food the event organisers consider in the first place, the structural limitations on food storage at the event, and aspects of the consciouslystructured customer interface, such as menu descriptions, pricing tactics and how food is displayed at the venue.

Thaler and Sunstein (2009) suggested proactively managing a choice architecture (or 'nudging') is a way of maintaining a firm commitment to freedom of choice while also helping people make better decisions for themselves (such as through healthy food choices). Further, they define nudges as aspects of the event architecture that alter people's behaviour in a predictable way without forbidding any options or significantly changing their economic incentives. This concept is particularly important in health promotion (and sport marketing) since the ways choices are presented influence what a decision-maker, such as a customer, chooses (Johnson et al., 2012). Examining choice architecture in the context of nutritional 
health promotion among spectators at sport events will lead to consideration of aspects such as what food and drink can be brought into the venue by spectators, the range of food and drink available for purchase, its price and tactics use to encourage purchase, as well as messages about eating and drinking in moderation. These factors are consciously constructed by people or organisations (also known as choice architects) who are responsible for arranging the context in which consumers make decisions (Thaler \& Sunstein, 2009). These agents, by structuring environments to influence what an audience chooses, have significant sway over perceptions, offerings and economic transactions, including those which have an impact on health, and especially so when spectators are relatively confined in a space, such as spectators within Olympic venues. Johnson et al (2012) explained that choice architects can influence choice in many ways, by varying the presentation order of choice alternatives, the order of attributes and their ease of use, and the selection of default options. This study proceeds on the observation that the 2016 Rio Olympic and Paralympic Games were explicitly framed by the organisers as an event that would be designed to promote healthy choices of food and drink for spectators, and they were able to design the food and drink environment as they wished.

\section{What is Healthy and Nutritious Food and Drink?}

An important question in the design of this research was - what counts as healthy and nutritious food and drink? We acknowledge that there is no universal categorisation of foods into these groups. Previous research has noted that consumers often categorise foods according to a good-bad dichotomy (such as healthy or unhealthy) based on specific food qualities (Oakes \& Slotterback, 2001; Provencher, Polivy, \& Herman, 2008; Rozin, Ashmore, \& Martwith, 1996). Thus, if 'a food gains a reputation as possessing a good (e.g. low calorie) or bad (e.g. fried) quality, the entire food item is likely to become designated as good or bad' (Carels, Harper, \& Konrad, 2006, p. 199). There are strong guidelines from numerous sources 
about what counts as healthy dietary habits. From a public health perspective, many studies show that a diet filled with processed foods, with high amounts of fat, sugar and sodium, often leads to poorer health outcomes than those which do not (Block, Scribner, \& DeSalvo, 2004; Lewis et al., 2005; Swinburn, Caterson, Seidell, \& James, 2004; Walker, Keane, \& Burke, 2010). However, we also acknowledge that in recent years contests over what counts as a healthy diet have become more prominent (see Dehghan et al., 2017).

In deciding to use these terms for the analysis, it was recognised that the terms 'healthy' and 'unhealthy' are prevalent in sport event evaluation literature (Drygas et al., 2011; Inoue, Berg, \& Chelladurai, 2015). We also defer to the Dietary Guidelines for the Brazilian Population, written by the Brazilian Ministry of Health (2014). This policy assumes a human right to health and healthy food and delineates between natural, minimally processed, processed and ultra-processed food. It states that 'natural or minimally processed foods, of different types and in large varieties, and predominantly of plant origin, are the basis of healthy diets' (p. 12). Natural foods are deemed to be obtained directly from plants or animals and do not undergo any alteration following their removal from nature. Minimally processed foods are "natural foods that have been submitted to ... processes that may subtract part of the food but which do not add oils, fats, sugar, salt or other substances to the original food' (p. 25). Consumption of processed foods should be limited, according to the policy, since 'the ingredients and techniques used in the manufacture of processed foods unfavourably alter the nutritional composition of the foods from which they are derived' ( $p$. 36). Lastly, ultra-processed foods are described as industrial formulations made entirely or mostly from substances extracted from foods, derived from food constituents ... or synthesised in laboratories from food substrates. The Ministry of Health recommends that Brazilians 'Avoid ultra-processed foods' (p. 39). The reasons for avoiding these foods are numerous and go beyond the potential for deleterious effects on an individual's bodily health. 
The Ministry of Health argues that their means of production, distribution, marketing, and consumption damage culture, social life, and the environment. The policy includes examples of ultra-processed food such as fatty, sweet or salty packaged snacks, biscuits (cookies), icecreams, candies and confectionery in general, cola and soft drinks, energy drinks; pizza and pasta dishes, burgers, hot dogs, and sausages. Therefore, with this policy guidance, the researchers concluded that that certain foods could reasonably be called 'unhealthy' for the purposes of this study.

\section{Methodological Considerations - An Interdisciplinary Project}

According to Doherty (2012) interdisciplinary collaboration is characterised 'by two or more investigators or teams of investigators, from different disciplines, working closely together designing the problem, determining the methodology to study it, analysing the data, and interpreting the findings' (p. 3). Bruhn (1995) writes that being interdisciplinary is a communal activity that 'melds the input of different disciplines into both the design and the execution of a unified project' (p. 337). Further, as Bruhn (2000) notes, it is the interaction between researchers from various disciplines that is fundamental to the creativity and new insights that are produced from interdisciplinary work.

Interdisciplinary work was suitable for various reasons. First, Doherty (2012) notes that interdisciplinary research is well suited for complex problems. The Olympic and Paralympic Games are at once a cultural, sporting and political event over seven years in the making involving a wide array range of transnational, national, regional and corporate organisations. This made it particularly suitable for interdisciplinary study. Disciplines of public health, marketing, psychology, policy studies, nutrition and event management all contribute to this multifaceted space. Second, there was an opportunity to examine an issue 
from different angles. Third, by acknowledging that 'the real problems of society do not come in discipline-shaped boxes' (Spence, 2012, p. 123), interdisciplinary research can directly confront the messiness of social problems. Whereas triangulation is a common aim of much multi-method qualitative research, it was important for this interdisciplinary approach to consider how various claims, rhetoric and practices might be mis-aligned, or argue against one another. Thus, the researchers in this present study were informed by critical public health perspectives (see LeBesco, 2011), event marketing and management perspectives (see Slack and Amis, 2004; Frisby, 2005) and nutrition literature (see Nestle, 2006). The subsequent results section merges different explanatory techniques (such as critical policy analysis, voices of spectators, photography and traditional audit data) to evaluate the way in which health was managed at Rio 2016. The researchers were from three countries and held a wide variety of expertise and interests, including sport management, sport science, marketing, nutrition, health policy and education. Four main types of data were examined; relevant policy, spectator menus, Rio 2016 venues and spectator interviews (see Table 1). These are discussed below.

\section{Examination of relevant policy.}

The Rio 2016 Food Policy was published in October 2014 by the Rio 2016 Organising Committee for the Olympic and Paralympic Games. This food and drink policy would ostensibly 'inform the food industry and other Rio 2016 Games stakeholders about the food and beverage services planned for the Olympic and Paralympic Games' (Rio 2016, 2014, p. 4). Also in 2014 the Brazilian government published the 'Dietary Guidelines for the Brazilian Population'. These documents were analysed in detail. Further, the Diagnostic Analysis for the Supply of Healthy and Sustainable Food for the 2016 Rio Olympic and Paralympic Games (Rio Food Vision, 2014), written by a consortium of organisations involved in the event was critically read. Where appropriate, various Olympic policies were 
also considered. For example, the ticket guidelines were examined (as half price tickets were available for obese spectators due to their medical condition), as were the 'conditions of entry' policy (since this affected what could be brought into or banned from venues).

\section{Venue analysis.}

Six researchers from the research group attended and analysed a wide variety of venues at the Olympic and Paralympic Games over the four-week period. The focus for this research was the 2016 Olympic Games (5 to 21 August) and Paralympic Games ( 7 to 18 September), hosted mainly in the city of Rio de Janeiro, Brazil, but also taking place in other cities around the country. Sampling was by necessity a mixture of purposive and convenient sampling, whereby all the major sites were frequented on numerous occasions, and a sample of smaller sites were also examined. Twenty two of 34 Rio sites were visited. Three aspects were considered in the venue analysis: 1) the food and drink available to purchase, 2) the menus and physical display of food and drink, and 3) the dining facilities. Data were gathered via field notes, photographs and videos, interviews and participant observation. During and following the event, the researchers discussed their findings with one another. There tended to be a large degree of convergence between the researchers regarding the findings.

\section{Menu analysis.}

Related to the venue analysis, a menu analysis involved a two-stage food audit to understand more about the extent to which healthy food was available at Rio 2016. First the researchers compared the official list of food and drink that was intended to be available at various venues (Rio 2016, 2016b) with the Brazilian Dietary Guidelines (2014) which have general categories of how processed particular foods and drinks are ('natural', 'minimally processed', 'processed' or 'ultra-processed'). This allowed the researchers to judge the relative healthiness or unhealthiness of various foods and drinks as defined by the Brazilian 
government policy. Second, through the event observation, the researchers evaluated how prominent and available these various options were for spectators.

\section{Interviews with spectators.}

Interviews were conducted with 30 individuals who attended Olympic or Paralympic events. Invitations to participate were conducted through face to face approaches and took place either inside or outside the sport venues through convenience sampling. Interviewees included adult respondents who had attended events at one of the two main venues, Barra Olympic Park and the Olympic Stadium. Interviewees were required to speak either Portuguese or English. The majority of respondents were Brazilian (24), with the remainder including spectators from England (3), New Zealand (2) and USA (1). The interviews were semi-structured and focused on questions regarding the interviewees' expectations of food and drink, their perspectives of the dining facilities, perceptions of how healthy and nutritious the food and drink was, whether a variety of Brazilian food and drink was available, and what they believed could be changed in future events. The responses were aggregated and considered in relation to the researchers' policy and venue evaluations.

\section{< INSERT TABLE 1 HERE >}

\section{Analysis}

Ideas about health, choice, food and drink were transformed leading up to and during Rio 2016. In the following analysis we show how a variety of concerted efforts were made to limit the availability of healthy foods, while a consciously designed food environment prioritised ultra-processed food to spectators. 
There is no specific template for interdisciplinary research, given the potential for different disciplines to be brought together. For this analysis, we examine the continuity and discontinuity of policy and practice across a range of sites over a period of time. Avoiding a traditional audit analysis in favour of a more flowing representation allows for the interplay, contradictions and disjunctures between various research sites to be displayed. The aim is to offer insight into the spectator implications of policy implementation - we focus on how ideas about health and choice were manifested through the event. Of the various disciplines integrated here, our emphasis is on public health (health promotion) as opposed to more traditional examinations of sport events (including marketing rationalities of customer satisfaction measures, brand image analysis or units sold). Indeed, as the analysis is presented, we encourage the reader to reflect on their own experience with food and drink at sport events, and consider the extent to which Karla Henderson's concern about the dominance of sport as entertainment and (and commerce and consumption) continues to influence both academia and real-world practice. Interdisciplinary research lends itself to data found from a variety of sources. As can be seen, various texts are present, ranging from researcher analysis, to imagery of the event, a menu audit and spectator voices. Coding for analysis involved preliminary scans of the data to identify health claims, choice claims and continuity and discontinuity in the various data sources. Initial analysis was deductive (see Braun, Clarke, \& Weate, 2016), whereby pre-determined themes emerged, though there was an opportunity for inductive analysis, whereby the researchers considered potential themes not in the original categories. Next, the most apparent and relevant themes were written in a draft narrative for all contributing authors to comment and feedback on. Once agreement was reached with all authors, these narratives have been distilled and woven into three themes; health and choice in policy, choice architecture at the event, and a discussion of the food and drink that eventually manifested at Rio 2016. Within these themes we identify and discuss the 
main problematic aspects identified in relation to the research questions. These subheadings were crafted to be narratively evocative and / or factually concise, in the hope the reader can quickly connect with them.

\section{Health and choice in Rio 2016's food policy}

\section{An aspiration for a healthy event.}

The Rio 2016 Taste of the Games' food policy (published 2 years before the Games) was replete with imagery of colourful fruit and vegetables. The cover page featured bananas and citrus fruit. The section named 'Our Values' (p. 13) featured a basket overflowing with corn, carrots, tomatoes, lettuce, cabbage, broccoli, aubergine, cauliflower, courgette and pepper. However, these photos were all 'stock' images - staged imagery of fruit and vegetables which can be purchased online. The imagery - colourful, bright, idealised fruit and vegetables evoked ideas of freshness and health. This imagery would bear no resemblance to the eventual food offerings for spectators at Rio 2016.

'Taste of the Games' emphasised that healthy food should be provided to all client groups, including athletes, media, volunteers, officials and spectators. Principle 2 of the policy stated 'Food offerings should be healthy, nutritious and balanced' (p. 3). Numerous other claims reinforced this idea, including 'The Food and Beverage (FAB) Functional Area (FA) plays an instrumental role in the Games because whilst fulfilling essential dietary needs .... Our mission is to efficiently deliver fresh, balanced and healthy food and beverage services' (p. 3-4). Further, the document claimed 'we have set goals to support healthy eating in our populations ... we also have a social responsibility to guide them to healthy choices...' (p. 13-14). The idea of healthy choice connotes a doubly-positive sentiment. That is, both health and choice are colloquially understand as unproblematic social goods. Further, 
claiming the event has a 'social responsibility' for health promotion does implicate the IOC and the event organisers directly in serious health matters, as distinct from being satisfied with traditional, convenient sport event food.

\section{The imposition of ultra-processed food sponsors into policy.}

Alongside claims of healthy choices noted above, there was a specific favouring of sponsors' rights at the Olympics. The policy stated that 'the food and beverage solution must also .... comply with the rights of Marketing Partners' (p. 3). The essence of these contractual rights could be seen in the obligation for food and drink providers to maximise sales of sponsors' products: 'The catering services proponent will be required to use best efforts to integrate as many of the Marketing Partner products into its menus as possible' (p. 18, italics added). The contradiction between guiding spectators 'to healthy choices' and integrating as many sponsor products into menus as possible is particularly problematic, as this obligation would potentially prioritise a narrow range of often ultra-processed food sponsors while marginalising other healthy food offerings. The emphasis on sponsors' brands was also in opposition to the principle that 'Brazilian products and recipes should have a prominent position in all menus to enrich the overall experience for all client groups' (p. 3, italics added). The policy claimed that this was an opportunity to 'help represent the cultural identity of the host ... highlighting the diversity and richness of Brazilian resources' (p. 3-4). The lack of Brazilian food and drink would become a common complaint from many interviewees.

Ideas about food, nutrition and health were present in the months leading up to the event, at the ticket purchase stage. Brazilians could purchase half price tickets if they were categorised as obese (Rio 2016, 2016a). While not explained in the official policy, this clause connected the event and ideas about health, including healthy eating. In conclusion, in the 
lead up to the event, official Rio policy on one hand paralleled official government policy about the importance of healthy food, while on the other, emphasised the need to satisfy commercial sponsorship contracts. Since many of the Rio 2016 sponsors, including CocaCola and McDonald's produce and promote a wide range of ultra-processed food and drink, there was an inherent contradiction within the policy.

\section{Choice architecture at the Games}

\section{Only ultra-processed food allowed in.}

Various managed processes and physical settings would guide people to points of food and drink consumption in the Olympic venues. These processes and settings were facilitated through a variety of techniques, rules, and instructions at the event sites. This started at the entry to venues. It was made clear in the ticket information provided to spectators that only 'non-perishable food ... for example, biscuit, cereal bars, baby food' would be allowed into the sites (2016a). Further, 'all liquids, drinks or beverages (alcoholic or not)' were prohibited (2016a). The experiences of the researchers during their site visits indicated this policy was generally adhered to during the Olympic Games. Intensive security processes were employed at venues which were very similar to typical airport screenings, including bag searches. This process included screening for food and beverages which did not adhere to the strict guidelines of the ticket policy. When this protocol is viewed in relation to the policy of a heavy emphasis on sponsors' products for sale within venues, it became apparent that the commercial motives were prioritised above the ostensible healthy eating agenda.

\section{An arena designed for fast food.}

Once inside the venue, the predominant interface for spectators and food at Rio 2016 were the main food stalls (along with mobile food and drink units at most venues). The main food stalls could be described as typical stadium canteens, though with very little imagery or 
presentation of actual food, as the heating of food often took place 'behind the scenes' out of view of the spectators. Many stalls displayed a distinct large sign above, such as 'Double cheeseburger', 'Pasta', 'Pizza', 'Drinks' or 'Snacks'.

\section{$<$ INSERT FIGURE 1 HERE >}

On the main counter of each stall were displays of the drinks that were on offer (Coca Cola, Powerade Zero, tea and bottled orange juice). There was often a small food warmer displaying a variety of small snacks that could be purchased, such as coxinha (fried chicken balls), kibe (fried meat balls), or pão de queijo (cheese bread). These products were often fried, with no vegetable or fruit content. Fruit and vegetable snacks, which had been so prominent in the Rio 2016 food policy, were nowhere to be seen. One interviewee summed up a common sentiment by saying: 'In Brazil ... we have a lot of fresh things that could be used in the Olympic Games.' Another respondent said 'I expected that because Brazil has so many fruits, colourful and delicious fruits, we would be able to show the world the richness of the flavours and fruits.' It was apparent many of the Brazilian spectators and tourists from overseas were disappointed to not see authentic, flavourful local food on the menus.

The physical manifestations of the dining facilities also played an important role in shaping perceptions about the event. Notwithstanding the seats inside stadiums and arenas themselves, most available seating at large venues consisted of red Coca Cola branded chairs and tables. Coca Cola sun umbrellas were also prominent at many outdoor venues. As a major sponsor of Rio 2016, Coca Cola had the power to promote their brands at venues. The tables, chairs and umbrellas were highly visible, in sharp contrast to the distinctly absence of fresh and healthy food and drink. Further, at the edge of the Barra Olympic Park was a large temporary construction painted red and white called The Coca Cola Zone. This was a physical manifestation of Coca Cola's sponsorship called 'ThatsGold'. The site was a grand 
display of Coca Cola's involvement with the Olympic Games and a point of consumption of Coca Cola. People would wait in a queue for up to an hour to enter the enclosed courtyard, at which time they were encouraged to proceed to a large counter where they would exchange their token for a commemorative golden Coca Cola bottle, full of the drink. There was also a Coca Cola truck which fans could have their photo taken on, Olympic torches which spectators could hold for photos, young Coca Cola representatives dancing around to upbeat music, a display of Coca Cola's historical involvement with the Olympic Games, and a Coca Cola store. This place was extremely popular throughout the entire Games with both adults and children. However, the site exclusively distributed Coca Cola, an ultra-processed drink, which the Brazilian Ministry of Health recommends people avoid consuming.

\section{Menus heavily promoted ultra-processed food and drink.}

The menus erected on stands outside the food stalls were the main source for spectators to get information about substantive (non-snack) products on offer. These menus usually had a prominent Coca Cola logo on the physical stand of the menu. Food and drink options were displayed in English and Portuguese. There were no images on the menus. Over time, as food stalls ran out of a specific item, white tape would be used to cover over the item on the menu.

\section{< INSERT FIGURE 2 HERE >}

Most interviewees criticised the lack of healthy food. There were instances of 'family meals' being offered. However, the food and drink involved was ultra-processed, including hot dogs, Coca Cola and a pudding with a high sugar content. One interviewee said: 'There was only fast food, and by the end of the event I needed to eat real food.' Another said: 'I did not notice any healthy options. If they did, it was not very well displayed.' Related to this was 
a common perception that the food on offer was very expensive, especially so for local Brazilian spectators who were more familiar with local prices. For example, a double cheeseburger was 18 Brazilian reais and a hot dog was typically 13 reais, which were perceived to be very expensive given the extremely limited range of options. Similarly, bottled water was 8 reais, with Coca Cola 10 reais. Given that spectators typically spent many hours at venues, those interviewed were generally resigned to paying the prices, rather than not eating, or dehydrating in the often hot climate.

\section{Delivery problems and angry customers.}

There were also major disruptions to the supply of food to various venues. In the early days of the Olympic Games there were many complaints about the lack of food on offer. As a result, the organisers sometimes allowed spectators to leave the venue to search for food and drink outside of the venues. Even when products were available, the range was disappointing for spectators. An interviewee commented 'I am vegetarian and yesterday (at the opening ceremony) while everyone had a choice of hamburger, hot dog, chicken sandwich, vegetarians only had the option of eating popcorn, peanuts or a sweet.' Despite various food shortages, there always seemed to be a bountiful supply of Coca Cola. These food shortages throughout the Olympic Games can be seen in relation to wider socio-political and economic forces surrounding Rio 2016. That is, despite premeditated plans to leverage the sponsors' contracts, organisational limitations meant that often there was insufficient food, no matter how processed it was.

A further issue of implementation regarding the process for purchasing food and drink led to spectators becoming very frustrated with the system. There were many complaints about the long queues to purchase food. There were problems with the food purchase system which was criticised by many spectators as being unclear and inefficient. This was because 
customers would be required to order food at one counter and then proceed to another counter to pick up their food. After a couple of days of significant frustrations and complaints, the organisers apologised and vowed to take remedial action.

Another researcher observation supported by interviewee feedback was that the food offered to spectators in the various Olympic sites could not be classed as 'fresh.' Out of all the locations visited, in the Barra Olympic Park, there was only one outlet which sold small fruit salads. However, these fruit salads were placed in a fridge with an opaque curtain, which itself was in a small nondescript shop in the corner of the main dining area. There was no effective signage to direct spectators to this place, and only one spectator interviewed (out of 30) was aware it existed. Some independent food trucks were allowed into various premises. However, the main foods available from these food trucks were burgers and hot dogs, which would also be classified as ultra-processed.

\section{< INSERT FIGURE 3 HERE >}

Regarding water provision, at some venues, such as the Olympic Stadium, free water fountains were in abundance. However, at other venues such as the Deodoro Park and the Olympic Park, there was no apparent free water. There was also no signage directing spectators to where they could attain free water, despite the IOC requiring free water provision in the Host City Contract Operational Requirements. Skol beer and Coca Cola stalls were in abundance, and bottled water was displayed in various fridges for purchase. There was no obvious place to access water. The researchers witnessed people of all ages in this venue, including many young toddlers who were drinking the free Coca Cola provided to them.

\section{Reactions to the lack of healthy choices.}


When confronted with a relatively limited choice of a large amount of ultra-processed food and drink which could reasonably be categorised as unhealthy, it was apparent that the spectators' need for food ensured they would duly choose from the limited menus. The researchers saw no acts of resistance against the limited choice, aside from some respondents mentioning they were eating as little as possible. Therefore, it was clear that aside from the unavailability of some of the food on the menu, the emphasis on sponsors' products dominated throughout both the Olympic and Paralympic Games. That is, the physical manifestations of choice architecture at the Rio 2016 venues emphasised the ultra-processed products of sponsors above fresh, healthy and nutritious food and drink.

\section{Analysis of the food and drink available}

\section{An array of unhealthy, junk food.}

It would eventuate that claims about 'fresh, healthy, Brazilian food and drink' would become subservient to the emphasis on sponsors' products in virtually all spectator environments at Rio 2016. It was clear from the menu audit that that the vast majority of food and drink presented to consumers at Rio 2016 could be classed as ultra-processed, food that the Brazilian Mistry of Health recommends avoiding (see Table 2). This finding, aside from being an apparent policy failure, has real implications for spectators who attended the event. Given the deleterious health consequences linked to ultra-processed food, we conclude here that most of the food offered to spectators was unhealthy.

\section{< INSERT TABLE 2 HERE >}

This finding was corroborated in most of the interviews with spectators. One interviewee summed up the sentiment of many by saying 'these Olympics - from food and drink consumption and the corporate sponsorship that I have seen - don't promote healthy living 
and that's a disappointment ... I would not call it healthy food.' Another interviewee acknowledged the commercial structure and imperative of the event:

I think it's because of money. The hot dogs, the cheeseburgers, Coca Cola, McDonald's is in the Olympics because of the money. The industrialists have money. And for the IOC, maybe another [healthier] company wouldn't have the same power.

Most food for sale was either processed or ultra-processed, and contained little or no fruit or vegetables (which were so plentiful in the Taste of The Games policy). Interviewees often expressed shock and disappointment at the perceived poor quality of food on sale. Further, many interviewees commented that there was no 'real' Brazilian cuisine that could be purchased to eat as a meal. The interviewees often recalled seeing only burgers, pizzas, hotdogs and hamburgers for sale and typically described the offerings as 'junk food'. One said 'There was too much the same ... Hot dogs, cheese burgers and Coca Cola.' Another said 'I think there was no nutrition in that food and no fresh food. There was only pizza and soda, and Coke. There is no nutritious food, there is no options for the people.' Another common description about the food was 'It was popcorn, it was sodas, ice cream, hamburger, hot dogs ... normal junk food.'

\section{$<$ INSERT FIGURE 4 HERE $>$}

\section{The dominance of Coca Cola and Skol beer.}

With specific reference to drinks, at all venues there was a variety of high sugar, low sugar and sugar-free drinks to purchase. Most of the visible branding at the venues was simply the traditional Coca Cola logo. The Skol beer logo also appeared on menus and the beer stalls were painted in a bright yellow colour, similar to the colour of the Skol brand. The specific Coca Cola stalls did not have prominent displays of the variety of Coca Cola drinks available 
for spectators. It was very noticeable that most of the drinks for purchase were ultraprocessed. Coca Cola fridges held original Coca Cola, sugar free soda, bottled orange juice, water and ultra-processed tea drinks. Contrastingly, some text in the 'Taste Of The Games' policy had given an example of what could have occurred: 'Beach Volleyball at Copacabana beach would not be a complete experience without aqua de coco served in fresh coconut' ( $p$. 16). However, coconut water was not seen at either the beach volleyball or at any other venues. One respondent said 'For drink the first thing you see was Coca Cola ... Coca Cola everywhere.' Another lamented 'You can only drink water, and it's so expensive, or you can drink Coke, or beer. The worst thing in the Olympics is the food.'

\section{Conclusion}

The Rio 2016 Taste of the Games food policy acknowledged that 'Around the world, sporting events have a bad reputation for serving uninspiring food that has been heavily processed or fried' (Rio 2016, 2014, p. 14). However, this study shows that the IOC and the Rio 2016 organisers served only to perpetuate this view. There were numerous points throughout the policy and practice processes where choices were made by policy makers, sponsors and organisers to structure the event in a way that spectators were severely constrained from having access to healthy, nutritious food and drink. Health is a concern for all people, and that the practices exhibited at Rio 2016 involved vulnerable spectators such as children, older adults and pregnant women make the findings presented here more alarming. Numerous actors are involved in this failure, with attention here directed towards the International Olympic Committee, the various food and drink sponsors and the event organisers. 
We conclude that Rio 2016 failed to fulfil its self-proclaimed 'social responsibility' of leading people towards healthy choices. Specifically, the failures included a) most of the prominent food and drink for spectators was 'ultra-processed', which the Brazilian Ministry of Health recommends avoiding, b) a Rio 2016 policy which claimed to promote 'healthy' food but also favoured sponsors' products to the exclusion of other healthy options, c) an entry policy involving the confiscation of spectators' own food and drink at the entry points to various venues, d) a narrow choice of food and drink and e) a poor selection of local, Brazilian food and drink. Given the abundant academic literature regarding serious health consequences of poor diets, health promotion rhetoric and IOC's own proclamations, we conclude here that a significant policy failure occurred.

There are transnational, national, regional and sport-specific policy implications stemming from this research. Transnational organisations such as the World Health Organisation should set clear guidelines for reasonable expectations regarding food and drink provision at mega sport events, especially so when such settings prohibit spectators from accessing their own food and may well include vulnerable groups, such as children, pregnant women and older adults. Sport-specific organisations such as the IOC and FIFA should ensure the health rhetoric they utilise through marketing communications is consistent in the events they endorse, host and arrange. Transnational sport organisations that target children to engage in their sports have a duty of care which should be particularly urgent as they are dealing with vulnerable cohorts. At both national and regional levels, governments have an obligation to promote health. Rio 2016 event organisers and many food and drink corporations did not translate government health policy into marketing. These corporations should be scrutinised by governments which often endorse, co-fund and promote these events. 
Theoretically, the central concept of choice architecture allowed the researchers to interrogate the complexity of the inter-linked factors that contribute to hosting large scale sport events. Instead of accepting the idea of 'choice' as unproblematic and positive, its critique allowed the researchers a useful foundation on which to base the analysis, and call into question policy claims which did not come to fruition. Choice architecture is not solely a domain of health promotion however. There is scope for this framework to be applied in other sport management contexts. These include areas as diverse as recruitment processes for boards and management where both applicants and managers are presented with and make choices (and in which some groups continue to be under-represented), sport participation settings where organisations might be conscious of falling memberships, and sport consumption settings where consumers are encouraged to be co-creators across a variety of platforms and options for watching sport. The structures in which people make choices are influential, and so deserve conscious attention.

This interdisciplinary research involved eight researchers, two languages, two events, twenty-two Brazilian sport venues, and various sources of data. These numerous aspects were necessary to connect and juxtapose formal policy claims with personal lived realities, and to show how policy, despite ostensibly good intentions, can be manipulated to produce distinctly adverse outcomes with potential real (ill) health effects. Given ongoing wider societal concerns about obesogenic environments (see Mason, Pearce, \& Cummins, 2017) the stark contrast between what was written in official health policy and what would eventuate at Rio 2016 raises serious concerns over the real impact of the Games on those who attended. Further, given that health promotion is both multi-dimensional and an increasingly prominent concern in the sports milieu, an interdisciplinary approach allowed the researchers to go beyond traditional boundaries of event analysis and evaluation. 
The study was completed by acknowledging the requirements for effective interdisciplinary research, including good communication, trust, compromise and creativity (Bruhn, 1995, 2000; Doherty, 2012; Oughton \& Bracken, 2009). However, two particular limitations of this project are worth noting for future research. First, the narratives presented here did not penetrate the 'behind the scenes' policy machinations which contributed to the eventual policy outcomes. This was partly due to attempted contact with Rio 2016 managers proving unsuccessful and an emphasis instead given to official policy claims in the study. Certainly, gaining access to the decision-making moments to see who makes decisions, and why and how they make them would bring greater clarity regarding why sports events might prioritise corporate sponsors over the health of spectators. Second, while the research team has and is endeavouring to leverage the findings from this research, there was much discussion about the possibility of incorporating an element of action research into future studies. That is, working with sporting organisations could be an effective way to create effective change to current health promotion practice at sports events.

Regarding the role of the IOC and the sponsors in this policy failure, it is worth noting the final official statement about food and drink at Rio 2016 took place three months after the Games. Staged as a press conference, the IOC's media department called it 'The success of the Olympic Games Rio 2016' (IOC, 2016b). A marketing spokesperson at the press conference claimed that IOC-commissioned research found that 'from an athlete and spectator point of view, the Rio experience was very much enjoyed and exceeded their expectations .... Awareness of the Olympic partners is still noticeable and the important role that they play in making the Games happen is widely recognised by the general population' (IOC, 2016b). Another spokesperson commented that 'it's the most universal, the most consumed Games according to our findings and research.' There was no mention of the problem in meeting the organisation's self-proclaimed social responsibility for health 
promotion. Therefore, one main hope of this research is that readers (from whatever discipline they are interested in) challenge the orthodoxy of health promotion claims about sport mega events that are in receipt of government funding.

In sum, this study reveals how a variety of specific policy actions and practices can subvert original health promotion rhetoric and marginalise health aims. We encourage health policy makers, sports funders and consumers to critically evaluate health claims made by sport events and sponsors. 


\section{References}

Block, J.P., Scribner, R.A., \& DeSalvo, K.B. (2004). Fast food, race / ethnicity, and income. American Journal of Preventive Medicine, 27(3), 211-217.

Boseley, S. (2017). Amsterdam's solution to the obesity crisis: no fruit juice and enough sleep. The Guardian, Retrieved from https://www.theguardian.com/society/2017/apr/14/amsterdam-solution-obesity-crisisno-fruit-juice-enough-sleep

Bragg, MA., Liu, PJ., Roberto, CA., Sarda, V., Harris, JL., \& Brownell, KD. (2013). The use of sports references in marketing of food and beverage products in supermarkets. Public Health Nutrition, 16, 738-742.

Bragg, MA., Miller, AN., Roberto, CA., Sam, R., Sarda, V., Harris, J.L., \& Brownell, K.D. (2018). Sports Sponsorships of Food and Nonalcoholic Beverages. Pediatrics. 141(4), $1-11$.

Brazil Ministry of Health (2014). Dietary Guidelines for the Brazilian Population. Retrieved from http://www.fao.org/nutrition/education/food-based-dietaryguidelines/regions/countries/brazil/en/

Braun, V., Clarke, V., \& Weate, P. (2016). Using thematic analysis in sport and exercise research. In B. Smith \& A. Sparkes (Eds.), Routledge handbook of qualitative research methods in sport and exercise (pp. 191-205). London: Routledge.

Bruhn, J.G. (1995). Beyond discipline: Creating a culture for interdisciplinary research. Integrative Physiological and Behavioral Science, 30, 331-341.

Bruhn, J.G. (2000). Interdisciplinary research: A philosophy, art form, artifact or antidote? Integrative Physiological and Behavioral Science, 35, 58-66. 
Carels, R.A., Harper, J., \& Konrad, K. (2006). Qualitative perceptions and caloric estimations of healthy and unhealthy foods by behavioral weight loss participants. Appetite, 46, 199-206.

Carter, M., Signal, L., Edwards, R., Hoek., J., \& Maher, A. (2013). Food, fizzy, and football: promoting unhealthy food and beverages through sport - a New Zealand case study. BMC Public Health, 13, 1-7.

Dehghan, M., Mente, A., Zhang, X., Swaminathan, S., Li, W., Mohan, V., Iqbal, R., Kumar, R., Wentzel-Viljoen, E., \& Rosengren, A. (2017). Associations of fats and carbohydrate intake with cardiovascular disease and mortality in 18 countries from five continents (PURE): A prospective cohort study. The Lancet. 390,(10107), 20502062.

Doherty, A. (2012). “It Takes a Village:” Interdisciplinary Research for Sport Management. Journal of Sport Management, 26, 1-10.

Drygas, W., Ruszkowska, J., Philpott, M., Bjorkstrom, O., Parkes, M., Ireland, R., Roncarolo, F., \& Tenconi, M. (2011). Good practices and health policy analysis in European sports stadia: results from the 'Healthy Stadia' project. Health Promotion International, 28, 157-165.

Frisby, W. (2005). The Good, the Bad, and the Ugly: Critical Sport Management Research. Journal of Sport Management, 19, 1-12.

Harris JL., Pomeranz JL., Lobstein, T., \& Brownell, K.D. (2009). A crisis in the marketplace: how food marketing contributes to childhood obesity and what can be done. Annual Review of Public Health, 30, 211-225.

Henderson, K.A. (2009). A paradox of sport management and physical activity interventions. Sport Management Review, 12, 57-65. 
Inoue, Y., Berg, B.K., \& Chelladurai, P. (2015). Spectator Sport and Population Health: A Scoping Study, Journal of Sport Management, 29, 705 -725.

International Olympic Committee (1999). Agenda 21: Sport for Sustainable Development. IOC, Lausanne.

International Olympic Committee (2010). The health legacy of the 2008 Beijing Olympic Games. Successes and recommendations. Edited by: Dapeng J, Ljungqvist A, Troedsson H. 2010, World Health Organisation, Geneva.

International Olympic Committee (2015). Olympic Charter. Retrieved from https://stillmed.olympic.org/Documents/olympic_charter_en.pdf International Olympic Committee (2016a). The Olympic Partner Programme. Retrieved from https://www.olympic.org/sponsors

International Olympic Committee (2016b). The success of the Olympic Games Rio 2016 Press conference. December 6, 2016. Retrieved from https://www.youtube.com/watch? $\mathrm{v}=\mathrm{rBbidySU} 1 \mathrm{r} 8 \& \mathrm{t}=2012 \mathrm{~s}$

Ireland, R., \& Watkins, F. (2010). Football fans and food: a case study of a football club in the English Premier League. Public Health Nutrition, 13(5), 682-687.

Johnson, E.J., Shu, S.B., Dellaert, B.G.C., Fox, C., Goldstein, D.G., Häubl, G., Larrick, R.P., Payne, J.W., Peters, E., Schkade, D., Wansink, B., \& Weber, E.U. (2012). Beyond nudges: Tools of a choice architecture. Marketing Letters. 23,(2), 487-504.

Lancet (2012). Editorial: Chariots of fries, The Lancet, 380, (9838), 188.

LeBesco, K. (2011). Neoliberalism, public health, and the moral perils of fatness, Critical Public Health, 21:2, 153-164,

Lewis, L.B., Sloane, D.C., Nascimento, L.M., Diamant, A.L., Guinyard, J.J., Yancey, A.K., \& Flynn, G. (2005). African Americans' Access to Healthy Food Options in South Los Angeles Restaurants. American Journal of Public Health, 95(4), 668-673. 
Mason, KE., Pearce, N., \& Cummins, S. (2017). Associations between fast food and physical activity environments and adiposity in mid-life: cross-sectional, observational evidence from UK Biobank. The Lancet Public Health, 3(1), e24-e33.

Nestle, M. (2006). Food marketing and childhood obesity - A matter of policy. New England Journal of Medicine, 354, 2527-2529.

Oakes, M.E., \& Slotterback, C.S. (2001). Judgements of food healthfulness: food name stereotypes in adults over age 25 . Appetite, 37, 1-8.

Oughton, E., \& Bracken, L. (2009). Interdisciplinary research: Framing and reframing. Area, $41,385-394$.

Pelly, F.E., O’Connor, H.T., Denyer, G.S., \& Caterson, I.D. (2011). Evolution of food provision to athletes at the summer Olympic Games. Nutrition Reviews, 69(6), 321332.

Pelly, F.E., Meyer, N.L., Pearce, J., Burkhart, S.J., \& Burke, L.M. (2013). Evaluation of Food Provision and Nutrition Support at the London 2012 Olympic Games: The Opinion of Sports Nutrition Experts. International Journal of Sport Nutrition and Exercise Metabolism, 24, 674-683.

Pettigrew, S., Rosenberg, M., Ferguson, R., Houghton, S., \& Wood, L. (2012). Game on: do children absorb sports sponsorship messages? Public Health Nutrition, 16(12), 21972204.

Provencher, P., Polivy, J., \& Herman, C.P. (2008). Perceived healthiness of food. If it's healthy, you can eat more! Appetite, 52(2), 340-344.

Rio Food Vision (2014). Diagnostic Analysis for the Supply of Healthy and Sustainable Food for the 2016 Rio Olympic and Paralympic Games. Rio Food Vision.

Rio 2016 Organising Committee for the Olympic and Paralympic Games (2014). Rio 2016, Taste of the Games. Retrieved from 
https://www.rio2016.com/sites/default/files/users/rio2016 files/rio-2016-taste-of-thegames_1.pdf

Rio 2016. (2016a). Olympic Tickets. Retrieved from https://www.rio2016.com/en/tickets

Rio 2016 (2016b). Tasty and traditional: Rio 2016 spectators spoilt for snack bar choice. Retrieved from https://www.rio2016.com/en/news/tasty-and-traditional-rio-2016$\underline{\text { snacks-for-spectators }}$

Rozin, P., Ashmore, M., \& Martwith, M. (1996). Lay American conceptions of nutrition: Dose insensitivity, categorical thinking, contagion, and the monotonic mind. Health Psychology, 15, 438-447.

Slack, T., \& Amis, J. (2004). “Money for nothing and your cheques for free?” A critical perspective on sport sponsorship. In T. Slack (Ed.), The Commercialisation of Sport (pp. 269-286). London: Frank Cass.

Smith, M., Jenkin, G., Signal, L., \& McLean, R. (2014). Consuming calories and creating cavities: beverages NZ children associate with sport, Appetite, 81, 209-217.

Soteriades, ES., Hadjichristodoulou, C., Kremastinou, J., Chelvatzoglou, F., Minogiannis, P., \& Falagas, M. (2006). Health promotion programs related to the Athens 2004 Olympic and Para Olympic games. BMC Public Health. 6, 47-10.

Spence, G.B. (2012). Coaching and cross disciplinary collaboration: More complexity and chaos? International Coaching Psychology Review, 7, 122-136.

Swinburn, B., Caterson, I., Seidell, J., \& James, W. (2004). Diet, nutrition and the prevention of excess weight gain and obesity. Public Health Nutrition, 7(1A), 123-146.

United Nations (2014). Report of the Special Rapporteur on the right of everyone to the enjoyment of the highest attainable standard of physical and mental health: Unhealthy foods, non-communicable diseases and the right to health. United Nations. Retrieved from http://www.ohchr.org/EN/Issues/Health/Pages/AnnualReports.aspx 
Walker, R.E., Keane, C.R., \& Burke, J.G. (2010). Disparities and access to healthy food in the United States: A review of food deserts literature, Health and Place, 16(5), 876884.

World Health Organisation (2012). WHO and the International Olympic Committee sign agreement to improve healthy lifestyles. World Health Organisation. Retrieved from http://www.who.int/mediacentre/news/releases/2010/ioc 20100721/en/

World Health Organisation (2016). Health Topics: Nutrition. World Health Organisation. Retrieved from http://www.who.int/topics/nutrition/en/ 